\title{
ЭФФЕКТИВНОСТЬ ИСПОЛЬЗОВАНИЯ ПРОБИОТИКОВ ДЛЯ ПОВЫШЕНИЯ ПРОДУКТИВНОСТИ КРОЛИКОВ
}

\section{A.V. Vostroilov, E.E. Kurchaeva, I.V. Maksimov}

\section{THE EFFICIENCY OF USING PROBIOTICS FOR IMPROVING RABBITS PRODUCTIVITY}

Востроилов А.В. - д-р с.-х. наук, проф., зав. каф. частной зоотехнии Воронежского государственного аграрного университета им. императора Петра I, г. Воронеж.

E-mail: alexandervostroilov@yandex.ru

Курчаева E.E. - канд. техн. наук, доц. каф. частной зоотехнии Воронежского государственного аграрного университета им. императора Петра I, г. Воронеж.

E-mail: alena.kurchaeva@yandex.ru

Максимов И.В. - канд. с.-х. наук, доц. каф. технологии хранения и переработки сельскохозяйственной продукции Воронежского государственного аграрного университета им. императора Петра I, г. Воронеж.

E-mail: alena.kurchaeva@yandex.ru

Цель исследований - установление влияния пробиотических препаратов серии "Ветом» на повышение продуктивности и физиологического статуса кроликов. Задачи исследований: изучить интенсивность роста кроликов и интерьерные показатели на фоне использования проибиотических препаратов серии «Ветом», а также определить мясную продуктивность кроликов. Для проведения научнохозяйственного опыта в условиях частного хозяйства Воронежской области («О.В. Кузнецова») в 2018 году методом пар-аналогов было сфрормировано 4 группы кроликов самцов (помеси, полученные при скрещивании пород советская шиншилла и новозеландская красная) в возрасте 45 суток. Кролики контрольной группы получали комбикорм ПЗК-92, а в рацион опытных групп дополнительно вводили пробиотические препараты: 2-я группа получала пробиотический препарат «Ветом 3.0» (50 м2 на 1 ке веса); 3-я группа - пробиотический nрenapam «Bетом 3.0» в (75 ме на 1 ке веса); 4-я группа комплексный пробиотический пре-
Vostroilov A.V. - Dr. Agr. Sci, Prof., Head, Chair of Private Zootechnics, Voronezh State Agricultural University named after Emperor Peter I, Voronezh. E-mail: alexandervostroilov@yandex.ru

Kurchaeva E.E. - Cand. Techn. Sci., Assoc. Prof., Chair of Private Zootechnics, Voronezh State Agricultural University named after Emperor Peter I, Voronezh.

E-mail: alena.kurchaeva@yandex.ru

Maksimov I.V. - Cand. Agr. Sci., Assoc. Prof., Chair of Technology of Storage and Processing of Agricultural Production, Voronezh State Agricultural University named after Emperor Peter I, Voronezh. E-mail: alena.kurchaeva@yandex.ru

nарат на основе препаратов «Ветом 3.0» 8 дозировке 35 мг и «Ветом 1.1» в дозировке 35 мг на 1 кг веса. Ввод в рацион пробиотических препаратов оказал положительное влияние на сохранность и интенсивность роста живой массы молодняка кроликов. Сохранность в опытных группах составила: 90 \% (2-я груnna) и 100 \% (3-я и 4-я группы). Максимальный прирост живой массы был отмечен в 3-й и 4-й группах и превышал данный показатель на 602,0 г, или 20,56 \%, и 646,0 г, или 22,07 \% контрольной группы. У кроликов опытных групп на конец откорма (120 суток) зафиксировано увеличение количества гемоглобина относительно контрольной группь: у особей 2-й группы на 1,91 \%, 3-й и 4-й группы на 2,98 и 6,08 \%. Максимальный убойный выход (61,90\%) зафиксирован у 4-й группы особей и был на $4,27 \%$ выше, чем в контрольной группе (59,36\%). Исследования по использованию комплексного пробиотического препарата серии «Ветом» представляют научный и практический интерес и подтверждают актуаль- 
ность его использования в отрасли кролиководства.

Ключевые слова: кролики, пробиотические комплексы, интенсивность роста кроликов, среднесуточный прирост, сохранность, продуктивность, убойный выход.

The aim of the research was to establish the effect of probiotic drugs series "Vetom" to increase the productivity and physiological status of rabbits. The objectives of the research were to study the growth rate of rabbits and interior indicators against the background of using probiotic drugs of "Vetom" series, as well as to determine rabbits' meat productivity. For carrying out scientific and economic experiments in the conditions of private farm of Voronezh Region ("O.V. Kuznetsova") in 2018 4 groups of male rabbits (crossbreeds obtained by crossing the breeds Soviet chinchilla and New Zealand red) were formed by the method of pairsanalogues, at the age of 45 days. The rabbits of the control group received mixed feed PZK-92, and in the diet of experimental groups additionally probiotic drugs were introduced: group 2 received probiotic drug "Vetom 3.0" (50 mg per $1 \mathrm{~kg}$ of weight), in group 3 probiotic drug "Vetom 3.0" (75 mg per $1 \mathrm{~kg}$ of weight) was used, group 4 complex probiotic drug based on drugs: "Vetom 3.0" at a dosage of $35 \mathrm{mg}$ and "Vetom 1.1" at a dosage of $35 \mathrm{mg}$ per $1 \mathrm{~kg}$ of weight was introduced The introduction of probiotic drugs into the diet had a positive impact on the safety and intensity of growth of live weight of rabbits' young growth. The safety in experimental groups was $90 \%$ (group 2) and $100 \%$ (groups 3 and 4). The maximum gain in live weight was observed in the 3-rd and 4-th groups and exceeded this indicator by $602.0 \mathrm{~g}$ or $20.56 \%$ and $646.0 \mathrm{~g}$ or $22.07 \%$ of control group. The rabbits of experimental groups at the end of fattening (120 days) demonstrated an increase in the amount of hemoglobin: in individuals of the 2-nd group by $1.91 \%$, the 3-rd and the 4-th groups by $2.98 \%$ and $6.08 \%$. The maximum slaughter yield (61.90\%) was recorded in the 4-th group of individuals and was $4.27 \%$ higher than in control group (59.36\%). The research on using complex probiotic drug series "Vetom" are of scientific and practical interest and confirm the relevance of its using in the rabbit industry.
Keywords: rabbits, probiotic complexes, rabbit growth rate, average daily gain, safety, productivity, slaughter yield.

Введение. Известна положительная роль пробиотических препаратов в повышении усвоения питательных веществ и продуктивности молодняка сельскохозяйственных животных, что связано с активизацией защитных сил организма животных [1, 2].

Решающую роль при интенсификации животноводства, в том числе кролиководства, играет полноценное кормление животных, что нашло отражение в работах отечественных и зарубежных исследователей [3].

Развитие такого нового направления, как экобиотехнология, в области производства продукции животноводства позволило отказаться от применения антибактериальных средств, заменив их альтернативными препаратами - пробиотиками, которые обладают активностью в отношении патогенной микросрлоры [4-7].

Постановка молодняка на откорм и отъем от крольчихи - сложный период, когда крольчата испытывают стресс, который способствует возникновению очагов инфекционных заболеваний, преимущественно желудочно-кишечного тракта, что приводит к падению среднесуточных приростов живой массы и в целом ослаблению организма $[8,9]$. Применение различных кормовых добавок пробиотической природы является одним из важных факторов при откорме молодняка. Пробиотические препараты оказывают непосредственное влияние на метаболизм, а также способствуют повышению продуктивности и оказывают положительное влияние на качество получаемого мясного сырья. В связи с чем перед нами стояла задача оценить эффрективность использования пробиотических препаратов в кормовых рационах молодняка кроликов.

Цель исследований. Изучение влияния пробиотических препаратов серии «Ветом» на повышение продуктивности и физиологического статуса кроликов.

Задачи исследований: изучить интенсивность роста кроликов и интерьерные показатели на фоне использования проибиотических препаратов серии «Ветом», а также определить мясную продуктивность кроликов. 
Материалы, объекты и методы исследований. Научно-хозяйственный опыт проводили в условиях частного хозяйства «О.В. Кузнецова» Воронежской области в 2018 году. В качестве объектов исследования использовали помесное поголовье кроликов (советская шиншиллахновозеландская красная) в возрасте 45 суток, которые были сфрормированы в контрольную и опытные группы по 15 голов в каждой, методом пар-аналогов из клинически здоровых животных. Кормление животных осуществляли комбикормом ПЗК-92 (производитель АО «ВЭКЗ», г. Воронеж). Кроликов контрольной группы кормили только комбикормом, а в рациОН опытных групп дополнительно вводили пробиотические препараты путем растворения рассчитанной дозы в $100 \mathrm{~cm}^{3}$ воды перед утренним кормлением курсом 10 дней каждые 30 суток: 2-я группа получала пробиотик «Ветом 3.0» (50 мг на 1 кг веса), 3-я группа - пробиотик «Ветом 3.0» (75 мг на 1 кг веса), 4-я группа - комплексный пробиотический препарат на основе «Ветом 3.0» в дозировке 35 мг и «Ветом 1.1» в дозировке 35 мг на 1 кг веса. Доступ к воде кроликов всех групп был свободным.
Для оценки мясной продуктивности кроликов было забито по 3 головы в возрасте 120 сут по методике ВИЖ. Статистическую обработку результатов исследований проводили с использованием методов вариационной статистики по методу Н.А. Плохинского с использованием программы Microsoft Excel. Различия считались достоверными при $\mathrm{P}<0,95 ; \mathrm{P}<0,999$.

Результаты исследований и их обсуждение. Интенсивность роста кроликов - важный показатель развития организма, который способствует раскрытию их биоресурсного потенциала, зависящего от полноценности рационов кормления. В этом плане большой интерес представляет применение различных биодобавок - пробиотиков различного видового состава. Оценку интенсивности роста молодняка проводили циклично каждые 15 сут выращивания.

В наших исследованиях представлено применение пробиотических комплексов серии «Ветом» и комплексной пробиотической добавки на основе препаратов «Ветом 3.0» и «Ветом1.1» в составе рациона кроликов (табл. 1).

Интенсивность роста молодняка кроликов $\left(X \pm S_{x}\right)$, r

Таблица 1

\begin{tabular}{|c|c|c|c|c|}
\hline \multirow{2}{*}{$\begin{array}{c}\text { Возраст кроликов, } \\
\text { сут }\end{array}$} & \multicolumn{4}{|c|}{ Группа } \\
\cline { 2 - 5 } & 1 (контроль) & 2 & 3 & 4 \\
\hline 1 & $39,58 \pm 0,14$ & $39,60 \pm 0,17$ & $39,78 \pm 0,18$ & $39,54 \pm 0,16$ \\
\hline 45 & $1355,0 \pm 19,20$ & $1362,0 \pm 11,52$ & $1368,0 \pm 14,28$ & $1357,0 \pm 15,32$ \\
\hline 60 & $1510,0 \pm 13,24$ & $1555,0 \pm 14,41$ & $1574,0 \pm 13,22$ & $1585,0 \pm 10,22$ \\
\hline 75 & $1947,0 \pm 23,14$ & $1959,0 \pm 17,26$ & $1997,0 \pm 19,24$ & $2180,0 \pm 83,60$ \\
\hline 90 & $2326,0 \pm 10,11$ & $2369,0 \pm 12,10$ & $2511,0 \pm 10,19$ & $2678,0 \pm 12,33$ \\
\hline 105 & $2653,0 \pm 22,39$ & $2918,0 \pm 18,24$ & $2997,0 \pm 21,14$ & $3148,0 \pm 33,12$ \\
\hline 120 & $2927,0 \pm 20,54$ & $3354,0 \pm 22,33^{* * *}$ & $3529,0 \pm 20,12^{* * *}$ & $3573,0 \pm 7,52^{*}$ \\
\hline $\begin{array}{c}\text { Среднесуточный } \\
\text { прирост, г }\end{array}$ & $23,62 \pm 0,85$ & $27,90 \pm 0,88$ & $28,81 \pm 0,86$ & $29,75 \pm 0,81$ \\
\hline Сохранность, \% & 80,0 & 90,0 & 100,0 & 100,0 \\
\hline
\end{tabular}

Примечание. Здесь и далее: ${ }^{*} \mathrm{P}<0,95 ;{ }^{* * *} \mathrm{P}<0,999$.

Анализ данных таблицы 1 подтверждает положительное влияние пробиотических препаратов на интенсивность роста живой массы.

Через 75 суток от начала вскармливания пробиотических препаратов максимальный прирост живой массы был отмечен в 3-й и 4-й группах. В этих группах живая масса превышала соответствующий показатель контрольной группы на $602,0$ г, или 20,56 \% ( $<<0,999)$, и 646,0 г, или $22,07 \%$ ( $\mathrm{P}<0,95)$, что, вероятнее всего, связано с замедлением скорости роста и подтверждается исследованиями ряда авторов $[8,9]$. Следует от- 
метить, что включение комплексного пробиотика серии «Ветом» в состав рациона кроликов оказало положительное влияние на сохранность поголовья кроликов. Наиболее высокий показатель сохранности наблюдался у кроликов 3-й и 4-й групп, которые получали с рационом пробиотик «Ветом 3.0» в дозировке 75 мг/кг живой массы и комплексный препарат (на основе «Ветом 1.1» и «Ветом 3.0» в соотношении 1:1) в суммарной дозировке 70 мг г/кг живой массы. Таким образом, повышения сохранности можно добиться за счет включения в их рацион комплексной пробиотической кормовой добавки серии «Ветом» путем улучшения работы желудочно-кишечного тракта и повышения иммунного статуса организма.

Полноценность рационов питания и активность иммунной системы отражаются на показателях крови (табл. 2), которые можно рассматривать как фактор состояния метаболических реакций в организме кроликов.

\section{Морфологические показатели крови молодняка кроликов}

Таблица 2

\begin{tabular}{|c|c|c|c|}
\hline Группа & Гемоглобин, г/л & Эритроциты, 1012/л & Лейкоциты, 109/л \\
\hline \multicolumn{4}{|c|}{ В начале откорма (45 суток) } \\
\hline 1 (контрольная) & $112,90 \pm 1,22$ & $4,52 \pm 0,11$ & $7,83 \pm 0,03$ \\
\hline 2 & $113,10 \pm 1,14$ & $4,47 \pm 0,13$ & $7,73 \pm 0,08$ \\
\hline 3 & $113,87 \pm 2,32$ & $4,62 \pm 0,10$ & $7,97 \pm 0,08$ \\
\hline 4 & $114,12 \pm 1,17$ & $5,17 \pm 0,07$ & $7,87 \pm 0,02$ \\
\hline \multicolumn{4}{|c|}{ В конце откорма (120 суток) } \\
\hline 1 (контрольная) & $118,59 \pm 0,47$ & $4,95 \pm 0,07$ & $7,62 \pm 0,19$ \\
\hline 2 & $119,43 \pm 0,12^{*}$ & $5,78 \pm 0,10$ & $7,44 \pm 0,12$ \\
\hline 3 & $121,49 \pm 0,34^{\star \star *}$ & $5,83 \pm 0,05$ & $7,67 \pm 0,11$ \\
\hline 4 & $124,34 \pm 0,12^{\star \star *}$ & $5,82 \pm 0,09$ & $7,26 \pm 0,06$ \\
\hline
\end{tabular}

Установлено, что у кроликов опытных групп на конец откорма (120 суток) зафиксировано увеличение количества гемоглобина относительно контрольной группы: у особей 2-й группы на 1,91\% (P < 0,95), 3-й и 4-й группы на 2,98 и $6,08 \%$ ( $(\mathrm{<}<0,999)$ соответственно (табл. 2).

На синтез белка оказывает влияние активность ферментов аланинаминотрансферазы (АЛТ) и аспартатаминотрансфреразы (АСТ). Установлено, что ввод пробиотических препаратов повлиял на активность аспартатаминотранфре- разы и аланинаминотранферазы (табл. 3). В ходе опыта установлено, что у кроликов 4-й группы повышается активность аспартатаминотрансферазы с 34,7 до 51, 0 Е/л и аланинаминотрансферазы с 50,6 до 58,5 Е/л. Данная динамика подтверждает более интенсивное протекание белкового обмена в опытной группе.

На рисунках 1 и 2 представлено содержание общего белка, альбуминов и глобулинов в сыворотке крови подопытных кроликов при постановке на откорм и в конце опыта.

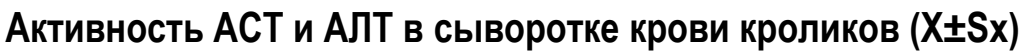

Таблица 3

\begin{tabular}{|c|c|c|c|c|}
\hline \multirow{2}{*}{ Группа } & \multicolumn{2}{|c|}{ АСТ, Е/л } & \multicolumn{2}{c|}{ АЛТ, Е/л } \\
\cline { 2 - 5 } & 45 суток & 120 суток & 45 суток & 120 суток \\
\hline 1 (контрольная) & $37,6 \pm 0,005$ & $39,0 \pm 0,006$ & $51,2 \pm 0,001$ & $54,7 \pm 0,002$ \\
\hline 2 & $36,9 \pm 0,003$ & $38,0 \pm 0,002$ & $49,8 \pm 0,021$ & $52,9 \pm 0,015$ \\
\hline 3 & $34,8 \pm 0,003$ & $44,0 \pm 0,002$ & $49,9 \pm 0,021$ & $54,4 \pm 0,015$ \\
\hline 4 & $34,7 \pm 0,003$ & $51,0 \pm 0,002$ & $50,6 \pm 0,021$ & $58,5 \pm 0,015$ \\
\hline
\end{tabular}




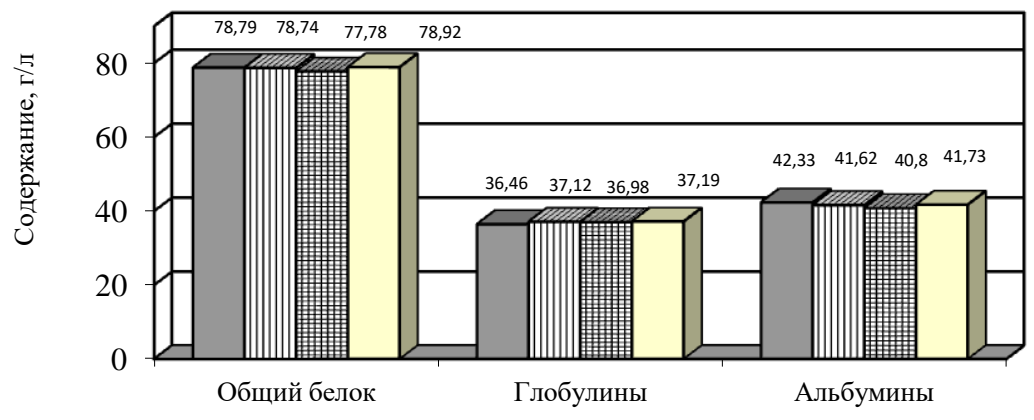

口1 группа

凹 2 группа

田 3 группа

口4 группа

Puc. 1. Биохимические показатели крови кроликов в начале опыта (возраст 45 суток)

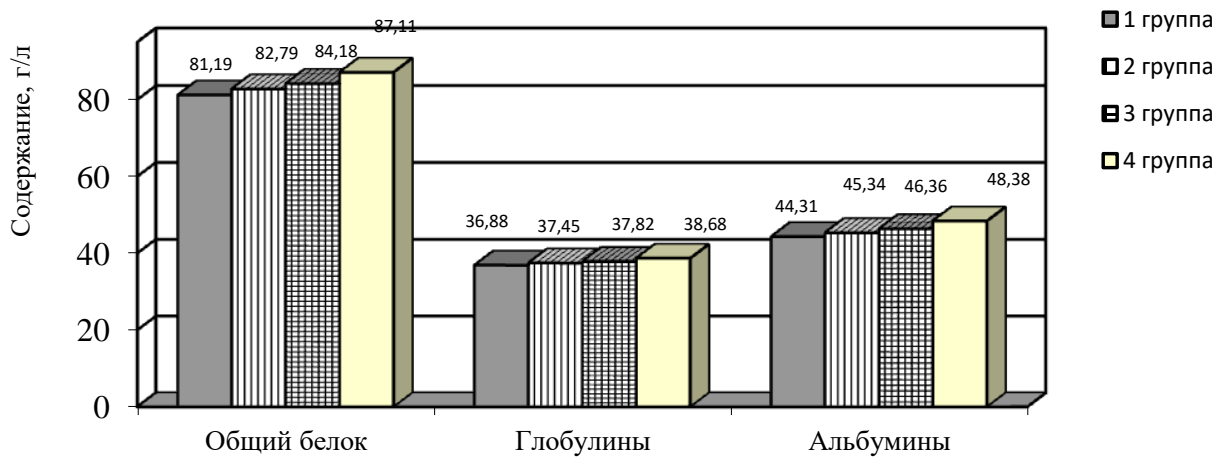

Puс. 2. Биохимические показатели крови кроликов в конце опыта (возраст 120 суток)

Было также зафиксировано повышение количества общего белка сыворотки крови у 4-й группы, которое составило 87,11 г/л (рис. 2) по сравнению с контролем (81,19 г/л).

В конце опыта был произведен контрольный убой кроликов с оценкой морфологического со- става согласно общепринятой методике. Максимальный убойный выход зафиксирован в 4-й группе и составил $61,90 \%$, что на 4,27 \% выше, чем в контрольной (59,36 \%) (табл. 4).

\section{Показатели контрольного убоя подопытных кроликов}

Таблица 4

\begin{tabular}{|l|c|c|c|c|}
\hline \multirow{2}{*}{ Показатель } & \multicolumn{4}{|c|}{ Группа } \\
\cline { 2 - 5 } & 1 (контроль) & 2 & 3 & 4 \\
\hline Предубойная живая масса, г & $2795,0 \pm 11,2$ & $3154,0 \pm 11,37$ & $3219,0 \pm 19,11$ & $3245,0 \pm 10,34$ \\
\hline Масса охлажденной тушки, г & $1659,0 \pm 10,3$ & $1908,0 \pm 20,11$ & $1979,0 \pm 21,33$ & $2009,0 \pm 12,4$ \\
\hline Убойный выход, \% & $59,36 \pm 0,11$ & $60,49 \pm 0,19^{* * *}$ & $61,50 \pm 0,13^{\star * *}$ & $61,90 \pm 0,14^{*}$ \\
\hline Индекс мясности & $2,97 \pm 0,78$ & $3,74 \pm 0,62$ & $4,19 \pm 1,24$ & $4,43 \pm 0,55$ \\
\hline
\end{tabular}

Выводы. Введение в рацион кроликов комплексного пробиотического препарата на основе «Ветом 3.0» и «Ветом 1.1» (в соотношении 1:1) в суммарной дозировке 70 мг/кг живой массы способствовало сохранности поголовья до 100 \% (4-я группа). Максимальный прирост живой массы был отмечен в 4-й группе и превышал данный показатель на 646,0 г, или 22,07 \%, по сравнению с контрольной группой. Также у кроликов 4-й группы на конец откорма (120 суток) зафиксировано увеличение количества гемоглобина на $6,08 \%$ относительно контрольной группы. Убойный выход $(61,90 \%)$ у кроликов 4-й группы был на 4,27 \% выше, чем в контрольной группе $(59,36 \%$ \%). Результаты проведенных исследований доказывают целесообразность при- 
менения комплексного пробиотического препарата в дозировке 70 мг/кг живой массы в отрасли кролиководства, что будет способствовать повышению фризиологического статуса подопытных кроликов и их продуктивных качеств.

\section{Литература}

1. Горковенко Л.Г., Юрина Н.А., Омельченко Н.А. [и др.]. Эфрфективность использования пробиотической добавки к корму «Бацелл-М» в рационе кроликов // Ветеринария Кубани. - 2016. - № 1. - С. 19-21.

2. Егорова С.В., Кирилюк П.К., Аристархова О.О. Использование комплексного пробиотика для пушных зверей // Стратегии и тренды развития науки в современных условиях. - 2017. - № 1 (3). - С. 124-126.

3. Балакирев Н.А., Калугин Ю.А. Кролиководство - перспективная отрасль животноводства // Ветеринария, зоотехния и биотехнология. - 2015. - № 7. - С. 20-23.

4. Омельченко Н.Н., Лысенко А.А., Омельченко Н.А. [и др.]. Использование отечественного пробиотика при выращивании кроликов // Труды Кубанского государственного аграрного университета. - 2015. - № 53. C. 194-198.

5. Абрамкова Н.В. Сравнительная эффективность применения спорообразующих пробиотиков в технологии выращивания поросят // Вестник КрасГАУ. - 2015. - № 8. C. 173-176.

6. Донкова Н.В., Донков С.А. Антагонистическая активность амилолитических штаммов бактерии Bacillussubtilis // Вестник КрасГАУ. - 2016. - № 7. - C. 173-179.

7. Донкова Н.В., Донков С.А., Кадетова М.Ю. Изучение устойчивости к антибиотикам бактерий рода Bacillus методом серийных разведений // Вестник КрасГАУ. - 2019. № 5. - C. 94-100.

8. Востроилов А.В., Курчаева Е.Е., Пащенко В.Л. Продуктивные качества кроликов при введении в рацион пробиотического препарата «Ветом 3.0» // Вестник Воронежского государственного аграрного университета. - 2018. - № 2 (57). - С. 76-82.

9. Майоров А.И., Скрябин С.О. Влияние пробиотиков «Оралин 35G» и «Ветом 2» на по- казатели неспецифической резистентности организма кроликов // Кролиководство и звероводство. - 2011. - № 6. - С. 28-32.

\section{Literatura}

1. Gorkovenko L.G., Jurina N.A., Omel'chenko N.A. [i dr.]. Jeffektivnost' ispol'zovanija probioticheskoj dobavki k kormu «Bacell-M» v racione krolikov // Veterinarija Kubani. 2016. - № 1. - S. 19-21.

2. Egorova S.V., Kiriljuk P.K., Aristarhova O.O. Ispol'zovanie kompleksnogo probiotika dlja pushnyh zverej // Strategii i trendy razvitija nauki v sovremennyh uslovijah. - 2017. № 1 (3). - S. 124-126.

3. Balakirev N.A., Kalugin Ju.A. Krolikovodstvo perspektivnaja otrasl' zhivotnovodstva // Veterinarija, zootehnija i biotehnologija. - 2015. № 7. - S. 20-23.

4. Omel'chenko N.N., Lysenko A.A., Omel'chenko N.A. [i dr.]. Ispol'zovanie otechestvennogo probiotika pri vyrashhivanii krolikov // Trudy Kubanskogo gosudarstvennogo agrarnogo universiteta. - 2015. - № 53. - S. 194-198.

5. Abramkova N.V. Sravnitel'naja jeffektivnost' primenenija sporoobrazujushhih probiotikov $\mathrm{v}$ tehnologii vyrashhivanija porosjat // Vestnik KrasGAU. - 2015. - № 8. - S. 173-176.

6. Donkova N.V., Donkov S.A. Antagonisticheskaja aktivnost' amiloliticheskih shtammov bakterii Bacillussubtilis // Vestnik KrasGAU. 2016. - № 7. - S. 173-179.

7. Donkova N.V., Donkov S.A., Kadetova M.Ju. Izuchenie ustojchivosti $k$ antibiotikam bakterij roda Bacillus metodom serijnyh razvedenij // Vestnik KrasGAU. - 2019. - № 5. S. 94-100.

8. Vostroilov A.V., Kurchaeva E.E., Pashhenko V.L. Produktivnye kachestva krolikov pri vvedenii $v$ racion probioticheskogo preparata «Vetom 3.0» // Vestnik Voronezhskogo gosudarstvennogo agrarnogo universiteta. 2018. - № 2 (57). - S. 76-82.

9. Majorov A.I., Skrjabin S.O. Vlijanie probiotikov «Oralin 35G» i «Vetom 2» na pokazateli nespecificheskoj rezistentnosti organizma krolikov // Krolikovodstvo i zverovodstvo. 2011. - № 6. - S. 28-32. 